\title{
IN SITU SPECIATION OF NICKEL IN HYDROUS MELTS EXPOSED TO EXTREME CONDITIONS
}

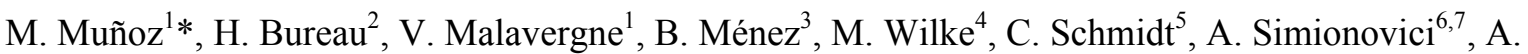 \\ Somogyi $^{6}$ and F. Farges ${ }^{1,8}$ \\ ${ }^{1}$ Laboratoire des Géomatériaux, CNRS FRE 2455, Université de Marne-La-Vallée, France \\ ${ }^{2}$ Laboratoire Pierre-Süe, CEA, Saclay, France \\ ${ }^{3}$ Laboratoire de Géosciences Marines, IPG, Paris, France \\ ${ }^{4}$ Institut fuer Geowissenschaften, Potsdam Universitaet, Germany \\ ${ }^{5}$ GeoForschungsZentrum Potsdam, Germany \\ ${ }^{6}$ ESRF, Grenoble, France \\ ${ }^{7}$ Laboratoire des Sciences de la Terre, ENS, Lyon, France \\ ${ }^{8}$ Department of Geological and Environmental Sciences, Stanford University, USA
}

\section{A9720 - Revised manuscript}

\begin{abstract}
In situ high-temperature and high-pressure XAFS experiments were performed at the $\mathrm{Ni}$ $K$-edge, at the ID22 $\mu$-beamline of the ESRF (Grenoble, France). The experimental setup consists of an externally heated "Bassett-modified" hydrothermal diamond-anvil cell. The sample chamber is loaded with a water-saturated haplorhyolitic glass: $\left(\mathrm{NaAlSi}_{3} \mathrm{O}_{8}\right)_{47}\left(\mathrm{KAlSi}_{3} \mathrm{O}_{8}\right)_{21}\left(\mathrm{SiO}_{2}\right)_{32}$, together with an aqueous $\mathrm{NiCl}_{2}$-solution $(0.35 \mathrm{~mol} / \mathrm{L})$ and an air bubble. The experiment is carried out to a temperature $(\mathrm{T})$ of $780{ }^{\circ} \mathrm{C}$, and the corresponding hydrostatic pressure $(\mathrm{P})$ is calculated to be around $520 \mathrm{MPa}$, based on the equation of state of water. $\mu$-XANES spectra are then collected in situ in the silicate melt and in the aqueous phase. Spectroscopic data are first interpreted in terms of speciation. At the experimental P-T conditions, nickel is essentially four-coordinated in the hydrous melt, whereas its coordination is 5 in the glass. Moreover, based on the theoretical description of the absorption edge, the XANES spectra are used to derive the "fluid/melt" partitioning coefficient for nickel $(0.22 \pm 0.05)$, as well as the density of the hydrated melt $\left(0.9 \pm 0.5 \mathrm{~g} / \mathrm{cm}^{3}\right)$.
\end{abstract}

PACS ref: 61.10.Ht, 91.35.Gf, 91.65.Nd

* e-mail:munoz@oreka.com 


\section{Introduction}

Structural and thermodynamical properties of hydrous silicate melts are of major interest for understanding fundamental geological processes related to explosive volcanic eruptions. Particularly, information concerning trace element speciation, and "fluid/melt" partitioning behavior, is required for understanding the transport properties as well as the geochemical processes controlling the formation of deep Earth magmas. Also, information concerning the density of hydrous silicate melts is required to better understand the dynamic properties related to the ascension of "highly-hydrated" magmas. One way to obtain such information is to perform in situ experiments using a hydrothermal diamond-anvil cell. That method is particularly adapted for the study of hydrous silicate melts [1], and can typically reach temperatures to $1000{ }^{\circ} \mathrm{C}$ and pressures to 1-2 GPa.

\section{Experimental}

In situ high-temperature and high-pressure experiments are performed using a "Bassettmodified" hydrothermal diamond-anvil cell (HDAC). The sample chamber is loaded with a water-saturated glass of haplorhyolitic chemical composition: $\left(\mathrm{NaAlSi}_{3} \mathrm{O}_{8}\right)_{47}\left(\mathrm{KAlSi}_{3} \mathrm{O}_{8}\right)_{21}\left(\mathrm{SiO}_{2}\right)_{32}$. Then, an aqueous $\mathrm{NiCl}_{2}$-solution $(0.35 \mathrm{~mol} / \mathrm{L})$ is added with an air bubble in the sample chamber (see Fig. 1, left). The $\mathrm{H}_{2} \mathrm{O}$ "liquid/vanor" homogenization temnerature, measured before and after the heating run, is $295 \pm 10^{\circ} \mathrm{C}$. Consequently, at the exnerimental temnerature (i.e., $780{ }^{\circ} \mathrm{C}$ ), the nressure is calculated to be around $520 \mathrm{MPa}$, based on the equation of state of water [2]. At the melt state, the silicate nhase forms hydrated, and nearly-snherical "globules" in equilibrium with the aqueous nhase [1, 3] (see Fig. 1, right).

During the exneriment, $\mu$-XANES snectra are collected at the Ni $K$-edge in fluorescence mode (ID22 beamline, ESRF, France); an ontical monitoring of the samnle being systematically nerformed before and after data acquisition. We used $\mathrm{Si}(111)$ double crystals monochromator, and Kircknatrick-Baez focusing mirrors, so that the snatial resolution of the incident X-ray beam 
was $3 \times 5 \mu \mathrm{m}$. Also, XANES spectra were collected using $0.1 \mathrm{eV}$ steps in the pre-edge region and $0.5 \mathrm{eV}$ steps in the main edge crest region.

\section{Results and Discussion}

The normalized Ni $K$-edge XANES spectra collected for the hydrated melt and the quenched glass are first interpreted in terms of nickel speciation. Ab initio calculations were performed using the FEFF 8.28 package assuming the crystal structure of $\mathrm{NiO}$ (6-coordinated $\mathrm{Ni}$ ) and $\mathrm{NiCr}_{2} \mathrm{O}_{4}$ (4-coordiated $\mathrm{Ni}$ ); the XANES spectra being calculated using Hedin-Lundqvist potentials and default values for all options.

Based on experimental [4] and theoretical approaches, the absorption edge XANES spectra as well as the position of the first "EXAFS" oscillation (gray line), traduce essentially the presence of $\mathrm{NiO}_{4}$ moieties in the hydrous silicate melt (see Fig. 2). This important result shows that quenched glasses are not appropriate images of their corresponding melts. Also, the coordination numbers of nickel in hydrous melts as well as in anhydrous melts [5] are similar, suggesting that water does not highly affect the local structural environment of nickel under in situ conditions.

The sample density $(\rho)$ as well as the mass fraction of nickel $\left(x_{\mathrm{Ni}}\right)$ are then extracted from the $\mu$-XANES snectra (edge jumns uncorrected) using the following equation [6]:

$$
\alpha . \Delta \mu=\rho \cdot x_{\mathrm{Ni}} \cdot \Delta(\mu / \rho)_{\mathrm{Ni}}
$$

in which $\Delta(\mu / \rho)_{\mathrm{Ni}}$ is the variation of the mass absorntion coefficient before and after the edge, $\Delta \mu$ is the exnerimental edge jumn at the Ni $K$-edge (modeled using an arctangent; see Fig. 3), and $\alpha$ is an "attenuation factor" due to the exnerimental setun. More nrecisely, this attenuation factor traduces the constant thickness of the samnle, but also the non-linearity of the absorntion coefficient due to the absorntion of the X-ray beam by the diamonds, as well as the fluorescence detection at the rear of the HDAC. 
In order to determine $x_{\mathrm{Ni}}$ and $\rho$ under in situ conditions for the aqueous phase and the silicate phase, respectively, the attenuation factors are previously determined, based on the edge jumps of the different XANES spectra collected under ambient conditions:

- Concerning the aqueous phase, the nickel content and the density are well known before the experiment.

- Concerning the silicate phase, the density of the hydrous quenched glass can be estimated around $2.2 \mathrm{~g} / \mathrm{cm}^{3}$ (see [7]). Also, the nickel content is determined after the experiment, using $\mu$-PIXE (Particule Induced X-ray Emission) mapping (see [3]). Analyses were performed using the nuclear microprobe facility of LPS (CEA, Saclay, France).

Consequently, the "fluid/melt" partitioning coefficient obtained for nickel is $0.22 \pm 0.05$. Despite their important compatible character (i.e., crystal vs. melt; e.g., [8]), this result suggests a non-negligible mobilization of nickel by the aqueous fluid during the ascension of magmas, beyond the exsolution levels.

Also, the density of the hydrous haplorhyolitic melt at $780{ }^{\circ} \mathrm{C}$ and $520 \mathrm{MPa}$ is estimated to be $0.9 \pm 0.5 \mathrm{~g} / \mathrm{cm}^{3}$, suggesting a particularly important proportion of water in the melt structure. This study represents the first attempt to measure a hydrous melt density well above the glass transition temperature, involving a major contribution to a better understanding of the structural and macroscopic properties of highly-hydrated magmas in conditions prior to explosive eruptions. 


\section{REFERENCES}

[1] Shen, A.H. and Keppler, H., Nature 385, 710 (1997).

[2] Haar, L., Gallagher, J.S. and Kell, G.S., "NBS/NRC steam tables: thermodynamic and transport properties for vapor and liquid states of water in SI units" (Hemisphere publishing corp., New York 1984), p. 320.

[3] Bureau, H. et al., Nucl. Instr. Meth. Phys. Res. B. 210, 434 (2003).

[4] Farges, F., Brown Jr., G.E., Petit, P-.E. and Muñoz, M., Geochim. Cosmochim Acta 65, 1665 (2001).

[5] Muñoz, M., “Comportement d'éléments formateurs et modificateurs de réseau dans des magmas hydratés” (PhD thesis, Université de Marne-La-Vallée, France 2003), p. 247.

[6] Teo, B.K., "EXAFS: Basic Principles and Data Analysis (9th ed.)” (Springer-Verlag, Berlin 1986), p. 349.

[7] Ochs, F.A. and Lange, R.A., Science 283, 1314 (1999).

[8] Takahashi, E. Geochim. Cosmochim Acta 42, 1829 (1978). 


\section{FIGURE CAPTIONS}

Fig. 1. Haplorhyolitic melt in an aqueous $\mathrm{NiCl}_{2}$-solution $(0.35 \mathrm{~mol} / \mathrm{L})$, exposed to high temperature and high pressure.

Fig. 2. Comparison between the Ni $K$-edge theoretical XANES spectra for $\mathrm{NiO}_{4}$ and $\mathrm{NiO}_{6}$ clusters, and the experimental spectra collected in situ for the hydrated silicate melt and for the quenched glass.

Fig. 3. $\mu$-XANES spectra collected at the $\mathrm{Ni} K$-edge for the aqueous $\mathrm{NiCl}_{2}$-solution (up), and the haplorhyolitic phase (down), exposed to in situ (high-temperature/highpressure) and ambient conditions. 


\section{FIGURE 1}
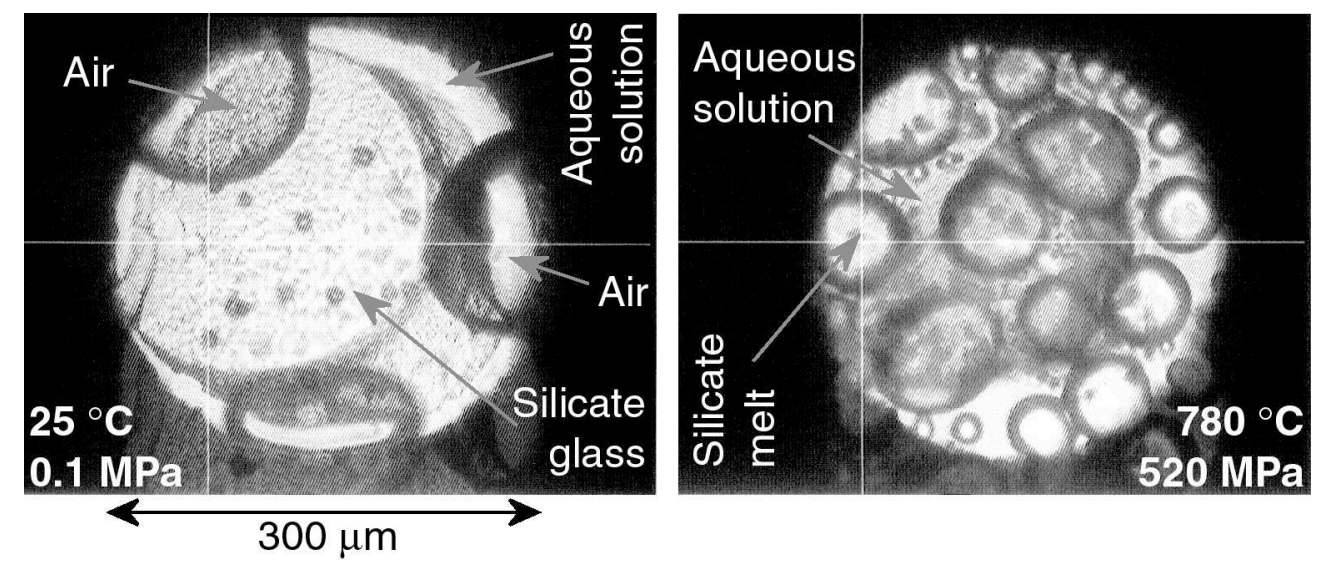


\section{FIGURE 2}

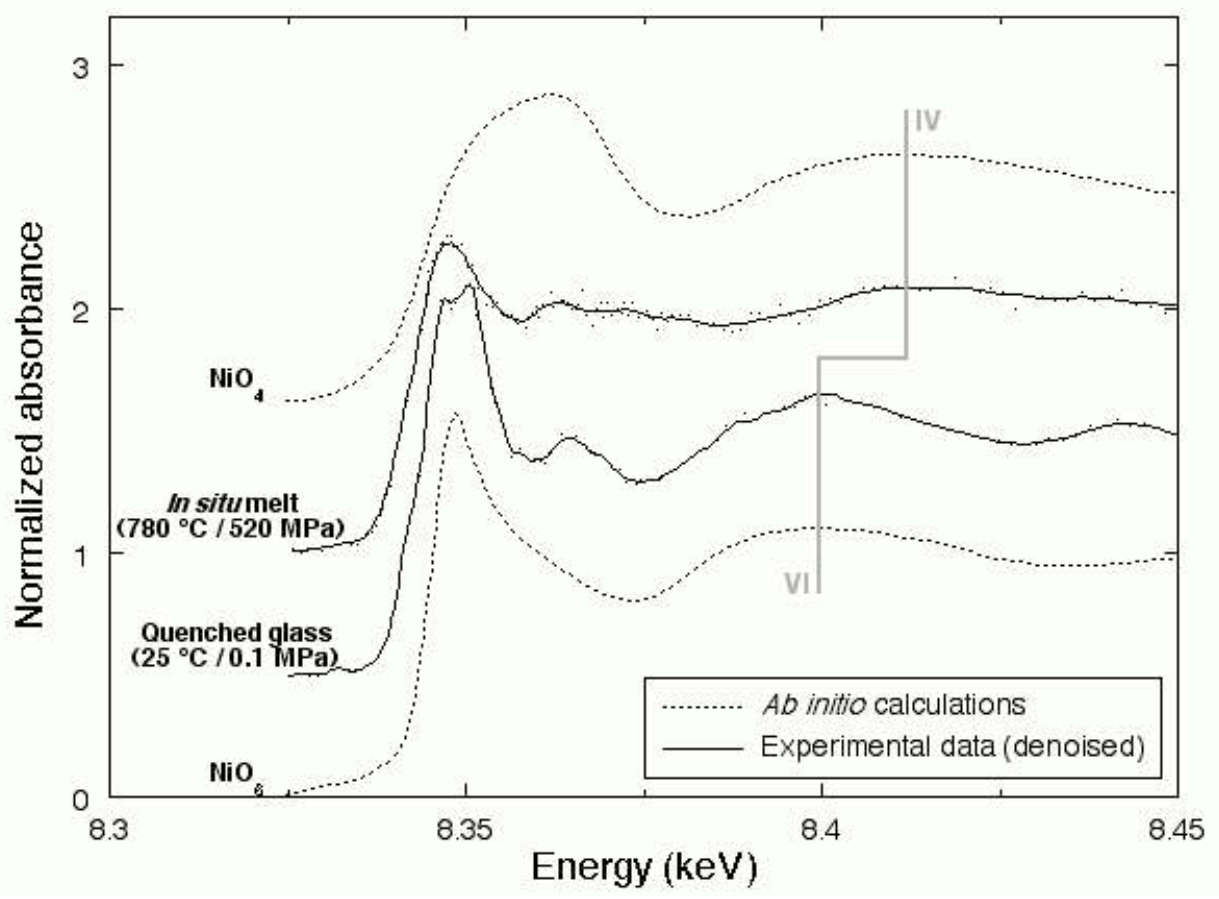




\section{FIGURE 3}
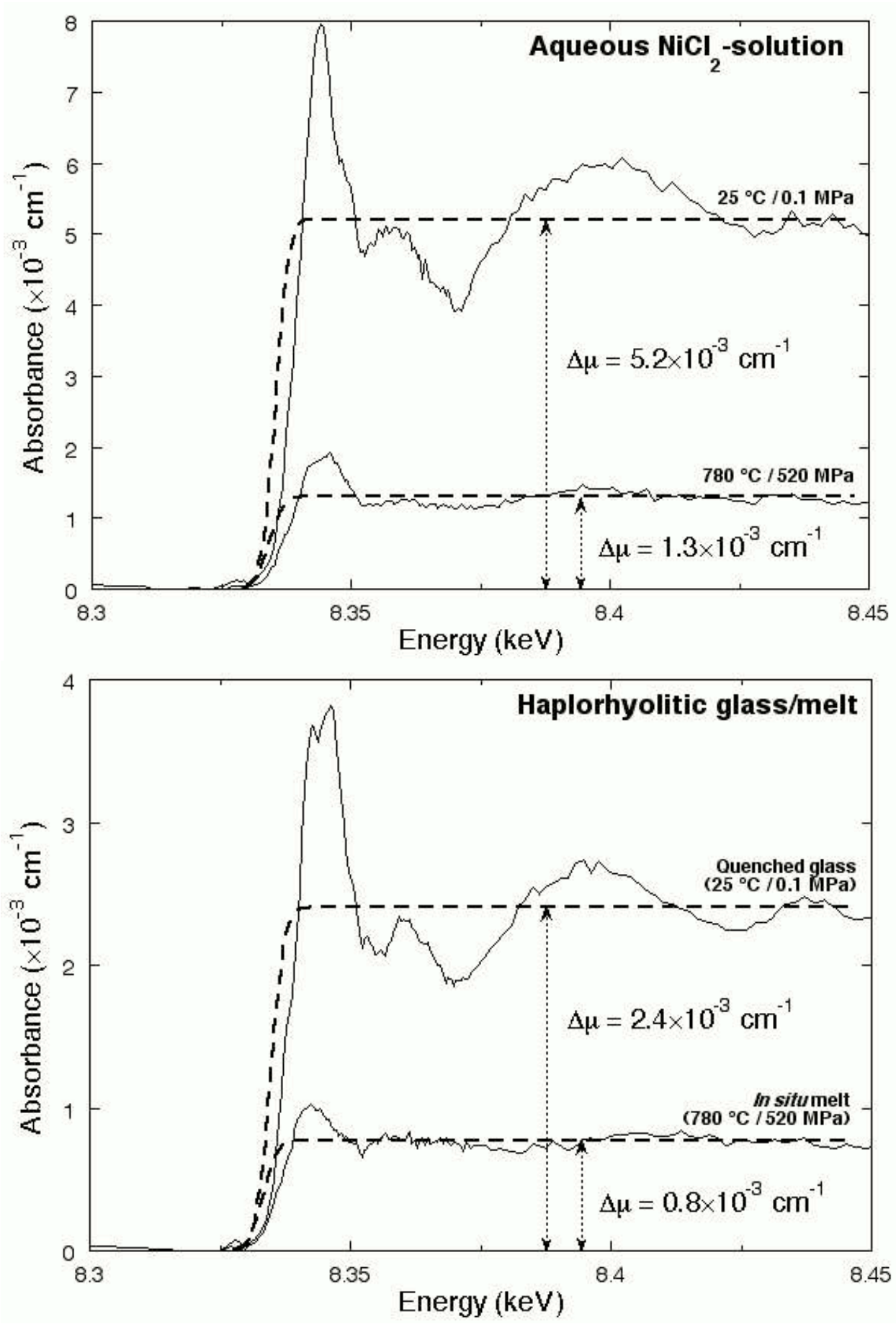